\title{
UM LUGAR PARA PENSAR A AMAZÔNIA? REVISITANDO A GEOGRAFIA NOVA E O PENSAMENTO CRÍTICO MILTONIANO
}

\author{
IS THERE A PLACE TO THINK ABOUT THE AMAZON ? \\ REVISITING THE « GEOGRAFIA NOVA » AND THE MILTONIAN CRITICAL \\ THOUGH
}

\author{
Y AURAIT-IL UNE PLACE POUR PENSER A L'AMAZONIE? \\ EN REVISITANT LA «GEOGRAFIA NOVA» ET LA PENSÉE CRITIQUE \\ MILTONIENNE
}

\section{Resumo}

A partir do aporte teórico de Milton Santos, o artigo mostra sua especial atenção em relação às regiões do Sul global e, nesse contexto, suas contribuições voltadas para a região amazônica. Com apoio em pesquisa bibliográfica e documental, foram consultados três tipos de fontes: a produção bibliográfica (livros, artigos e capítulos de livro) do geógrafo em referência; o acervo documental pessoal do autor, disponível no Instituto de Estudos Brasileiros/Universidade de São Paulo; e a produção bibliográfica (teses $e$ dissertações) a respeito da Amazônia inspirada em teorias miltonianas. A análise de todo esse material mostrou os elementos centrais do pensamento de Milton Santos, assim como a importância de sua contribuição intelectual para o entendimento de assuntos contemporâneos concernentes à região amazônica.

Palavras-chave: Geografias do Sul. Pensamento Crítico. Milton Santos. Região. Amazônia.

\begin{abstract}
Based on the theoretical contribution of Milton Santos, the article shows the special attention this author gave to the regions of the global South and, in this context, his contributions concerning the Amazon region. Supported by bibliographic and documentary research, three types of sources were consulted: the bibliographic production (books, articles and book chapters) of the geographer in reference; the personal documental collection of the author, available at the Institute of Brazilian Studies/University of São Paulo; and the bibliographic production (theses and dissertations) about the Amazon inspired by Miltonian theories. The analysis of all this material showed the central elements of Milton Santos' thought, as well as the importance of his intellectual contribution to the understanding of contemporary subjects concerning the Amazon region.
\end{abstract}

Keywords: Geographies of the South. Critical Thinking. Milton Santos. Region. Amazon.

\footnotetext{
${ }^{1}$ Geógrafo e Bacharel em Direito, Mestre em Planejamento do Desenvolvimento e Doutor em Geografia Humana. Professor Titular do Núcleo de Altos Estudos Amazônicos (NAEA) da Universidade Federal do Pará (UFPA), pesquisador do Conselho Nacional de Desenvolvimento Científico e Tecnológico (CNPq) e sócio efetivo do Instituto Histórico e Geográfico do Pará. E-mail: stclair@ufpa.br
} 


\section{Resumé}

À partir de la contribution théorique de Milton Santos, l'article montre l'attention particulière de cet intellectuel par rapport aux régions du Sud global et, dans ce contexte, ses contributions dirigées vers la région amazonienne. En tenant compte de recherches bibliographiques et documentaires, trois types de sources ont été consultées: la production bibliographique (livres, articles et chapitres de livres) du géographe précédemment mentionné; la collection documentaire personnelle de l'auteur, disponible à l'Institut d'Études Brésiliennes/Université de São Paulo; et la production bibliographique (thèses et dissertations) sur l'Amazonie élaborée à partir des théories miltoniennes. L'analyse de tout ce matériel a montré les éléments centraux de la pensée de Milton Santos, ainsi que l'importance de sa contribution intellectuelle à la compréhension des problèmes contemporains concernant la région amazonienne.

Mots-Clés: Géographies du Sud. Pensée Critique. Milton Santos. Région. Amazonie.

\section{INTRODUÇÃO}

A partir da obra do geógrafo brasileiro Milton Santos, tem-se como objetivo no presente trabalho ${ }^{2}$ mostrar a preocupação desse autor com as realidades socioespaciais do chamado Sul global e, mais especificamente nesse contexto, a atenção por ele reservada às particularidades socioespaciais de regiões como a Amazônia.

A metodologia que deu apoio à pesquisa considerou levantamento bibliográfico e documental em diferentes tipos de fontes, a saber: a) a produção bibliográfica do autor na forma de livros, artigos e capítulos de livros; b) o seu acervo documental pessoal disponível no Instituto de Estudos Brasileiros (IEB) da Universidade de São Paulo (USP); e c) a produção bibliográfica sobre a Amazônia, na forma de teses e dissertações inspiradas em teorias e conceitos miltonianos ${ }^{3}$.

O trabalho busca inicialmente reconhecer Milton Santos como uma das expressões intelectuais latino-americanas a pensar as assimetrias geográficas do mundo globalizado; em seguida, analisam-se formulações do autor, identificando-se preocupações e menções em relação à região amazônica; e, por fim, relacionam-se interpretações de autores diversos sobre a região com o legado de seu pensamento e de sua obra.

\footnotetext{
${ }^{2}$ Este trabalho sistematiza resultados parciais de investigação dos projetos de pesquisa "Um olhar geográfico em perspectiva: a Amazônia na abordagem do espaço como instância social" e "Geografias e epistemologias do sul: Amazônia, olhares críticos em perspectiva", ambos desenvolvidos como parte das atividades do autor na condição de bolsista de produtividade em pesquisa do CNPq, entidade do governo brasileiro voltada para o desenvolvimento científico e tecnológico. Uma versão da presente sistematização foi apresentada durante o XVII Encuentro de Geógrafos de América Latina, ocorrido em Quito (Equador) e publicada nos anais do referido evento (TRINDADE JR., 2019).

${ }^{3}$ Colaboraram com os levantamentos bibliográficos e documentais os seguintes discentes: Helbert Michel Pampolha de Oliveira (mestrando em Planejamento do Desenvolvimento, NAEA/UFPA), Gabriel Carvalho da Silva Leite (mestrando em Planejamento do Desenvolvimento, NAEA/UFPA) e Vanessa Oliveira da Silva (graduanda do curso de Geografia/bolsista de Iniciação Científica, CNPq/UFPA).
} 


\section{SITUANDO UM MARCO TEÓRICO DE ANÁLISE}

A preocupação com temas, particularidades e especificidades de regiões periféricas não é recente. Ela se faz presente em autores importantes e de referência na Geografia brasileira, como Josué de Castro e Manuel Correia de Andrade.

Em Josué de Castro, a temática da fome representa um esforço, já na década de 1940, de construção de uma Geografia integrada que permitisse uma visão de totalidade do Brasil de então, conforme pontua Moreira (2010), que reconhece nesse autor uma teoria geográfica de criação própria inspirada nos clássicos desta última ciência.

De forma mais específica ainda, aquele autor coloca a dependência colonial e o subdesenvolvimento como elementos explicativos importantes e considera a fome, seu tema de maior relevância, uma expressão biológica de males sociológicos e que tem íntima relação com as distorções econômicas do chamado subdesenvolvimento (CASTRO, 1984).

Não muito diferente é a contribuição de Manuel Correia de Andrade que, pautado inicialmente nas influências francesas de Paul Vidal de La Blache, voltava seus estudos para uma geografia de cunho mais regionalista, mas com uma diferenciação muito clara do que se convencionou chamar de geografia tradicional, dado o viés histórico-crítico nele muito presente, inspirado em matrizes teóricas preocupadas com questões sociais, e devido, também, o seu forte comprometimento político, conforme se pode apreender a partir de Marino (2014).

Em uma de suas obras de maior importância (ANDRADE, 1986), o geógrafo em referência demarca mesmo uma transição na Geografia brasileira rumo a uma abordagem crítica que iria se robustecer especialmente a partir dos anos 1980, momento em que a Geografia brasileira passou por grandes transformações.

Conhecedor da obra desses autores, Milton Santos figura, junto com eles, como um dos principais expoentes, no Brasil, daquilo que estamos chamando de "Geografias do Sul", entendidas aqui como uma leitura socioespacial das relações assimétricas entre regiões a partir da condição de subalternização dos países ditos "subdesenvolvidos", de "Terceiro Mundo" ou "economicamente dependentes", em face daqueles outros tidos como "centrais".

As atenções desse autor se voltaram para a edificação do que denominou de Geografia Nova (SANTOS, 1986), formada por temáticas diversas que consideraram desde estudos críticos sobre o espaço intraurbano, incluíram análises sobre o espaço brasileiro e sobre os países subdesenvolvidos, culminando com teorizações mais gerais a respeito do espaço, da cidadania e da Geografia como ciência, bem como, do atual período histórico da humanidade, definido por processos de globalização (Quadro 1). 
Quadro 1 - Milton Santos e a Geografia Nova: temas, preocupações e proposições

\begin{tabular}{|c|c|c|}
\hline Temas centrais & Preocupações & Principal Proposição \\
\hline $\mathrm{O}$ espaço & $\begin{array}{l}\text { - Relevância do espaço para a sociedade. } \\
\text { - Conceitos e teorias para a Geografia. }\end{array}$ & $\begin{array}{l}\text { - Espaço como instância } \\
\text { social. }\end{array}$ \\
\hline O subdesenvolvimento & $\begin{array}{l}\text { - Geografia do Terceiro Mundo: olhar } \\
\text { descentrado do mundo. } \\
\text { - Totalidade e particularidades socioespaciais. }\end{array}$ & $\begin{array}{l}\text { - Noção de } \\
\text { socioespacial. }\end{array}$ \\
\hline A urbanização & $\begin{array}{l}\text { - Dinâmicas urbanas em economias dependentes. } \\
\text { - Economia política da cidade e economia } \\
\text { política da urbanização. }\end{array}$ & $\begin{array}{l}\text { - Circuitos da economia } \\
\text { urbana e noção de } \\
\text { urbanização do território. }\end{array}$ \\
\hline A globalização & $\begin{array}{l}\text { - Período e meio técnico-científico } \\
\text { informacional. } \\
\text { - Lugar, região e globalização (fábula, } \\
\text { perversidade, possibilidade). }\end{array}$ & $\begin{array}{l}\text { - Ideia de uma outra } \\
\text { globalização. }\end{array}$ \\
\hline A cidadania & $\begin{array}{l}\text { - Modelo econômico e político de ordenamento } \\
\text { territorial. } \\
\text { - Modelo cívico como possibilidade de articular } \\
\text { território e cidadania. }\end{array}$ & $\begin{array}{l}\text { - Espaço como condição de } \\
\text { cidadania. }\end{array}$ \\
\hline
\end{tabular}

Elaboração: Saint-Clair Trindade Júnior com base em Santos (1979a, 1982a,1986, 1987, 1993, 2000a).

A partir dessas preocupações, Santos registrou em sua trajetória acadêmica uma densa reflexão sobre as realidades dos países do Sul, com contribuições importantes que incluem também análises sobre a Amazônia. No contexto de sua produção intelectual, algumas particularidades socioespaciais dessa região são reveladas em face dos processos de modernização e de urbanização que caracterizam o território brasileiro contemporâneo.

\section{UM PERCURSO BIBLIOGRÁFICO-DOCUMENTAL: ALGUNS RESULTADOS O LUGAR RESERVADO À AMAZÔNIA EM SANTOS}

No acervo do IEB/USP (Arquivo Instituto de Estudos Brasileiros [IEB], 2017) identifica-se um arquivo pessoal de Milton Santos com 81 documentos sobre a Amazônia. Agrupados por assuntos, revelam seu interesse por vários temas, sendo mais recorrentes os ligados à "mineração e grandes projetos", seguidos por aqueles que tratam de "ecologia, ecossistema e meio ambiente", de "cidades, rede urbana e urbanização" e de "colonização e fronteira econômica" (Tabela 1). 
Tabela 1 - Acervo Milton Santos: tema central sobre a Amazônia por documento

\begin{tabular}{clc}
\hline No. de ordem & \multicolumn{1}{c}{ Tema central do documento } & $\begin{array}{c}\text { No. de } \\
\text { documentos }\end{array}$ \\
\hline 1 & Mineração e grandes projetos & 22 \\
2 & Ecologia, ecossistema e meio ambiente & 15 \\
3 & Cidades, rede urbana e urbanização & 12 \\
4 & Colonização e fronteira econômica & 09 \\
5 & Migração e povoamento & 06 \\
6 & Populações, cultura e terras indígenas & 04 \\
7 & Reforma agrária, campesinato e estrutura fundiária & 04 \\
8 & Temas estruturais/gerais & 04 \\
9 & Industrialização, agroindústria e desenvolvimento & 03 \\
10 & Região e regionalização & 01 \\
11 & Sistema viário & 01 \\
\hline TOTAL & & $\mathbf{8 1}$ \\
\hline
\end{tabular}

Fonte: Elaborado a partir de levantamento no Arquivo IEB (2017).

O mesmo arquivo permite constatar as principais referências empíricas a que se associam os documentos. A grande maioria refere-se à Amazônia como um todo, e o restante demonstra o interesse do autor por estados da região; assim como por realidades bem mais específicas (Tabela 2).

Tabela 2 - Acervo Milton Santos: referências empíricas sobre a Amazônia por documento

\begin{tabular}{clc}
\hline No. de Ordem & Recorte Empírico do Conteúdo do Documento & No. de documentos \\
\hline 1 & Região amazônica & 57 \\
2 & Estado do Pará & 04 \\
3 & Carajás & 03 \\
4 & Estado de Rondônia & 03 \\
5 & Manaus & 03 \\
6 & Serra Pelada & 02 \\
7 & Estados de Rondônia, Amapá e Goiás & 02 \\
8 & Tucurú & 02 \\
9 & Marabá & 01 \\
10 & Norte de Mato Grosso & 01 \\
11 & Brasil & 01 \\
12 & Alto Xingu & 01 \\
13 & Estados do Pará e Maranhão & 01 \\
\hline TOTAL & & $\mathbf{8 1}$ \\
\hline
\end{tabular}

Fonte: Elaborado a partir de levantamento no Arquivo IEB (2017).

No interior de suas obras esse interesse se reafirma quando arrola conceitos e teorias e faz proposições que ajudam a entender a Geografia, o Brasil e o processo contemporâneo de globalização. Ao elaborar a teoria do espaço (SANTOS, 1986), por exemplo, mostra a importância de compreendê-lo como uma das instâncias da sociedade. Para o autor, não há estruturas cujo movimento subordinado seja dado de forma exclusiva pela instância econômica. Exemplifica seu raciocínio mostrando como, na Amazônia, a questão da segurança levou o Estado a tomar decisões de reordenar o espaço de maneira a assegurar a soberania; ainda que em prazo mediato tais ações tivessem implicações com o processo produtivo (SANTOS, 1986). 
Seu avanço teórico o levou também a considerar o território como forma-conteúdo, denominando-o de território usado, por sua natureza processual e por conter a vida de todos na sua dimensão global, nacional, regional e local (SANTOS, 1999). Define-se, assim, social e historicamente, como recurso, como condição e como base para a vida humana; diferentemente, portanto, do território sem adjetivação, associado ao exercício da soberania e sobre o qual se projeta o controle político. Para isso, no mesmo trabalho, menciona a Amazônia para exemplificar essa conceituação.

Seu olhar descentrado permitiu também estabelecer formulações inovadoras sobre o mundo e sobre o Brasil. Em uma delas, inclusive, sustenta que foi a partir da Amazônia que compreendeu "como é que São Paulo se instala no Brasil como capital geral da nação, e como conseguiu esse comando único sobre todo o território" (SANTOS, 2000b, p. 117).

Em trabalho da década de 1970 (SANTOS, 1979b) já demonstrava a preocupação com o que vinha acontecendo nessa região ao analisar a construção do que chamou de espaço transnacionalizado no Brasil; preocupação essa reforçada em outras sistematizações em décadas seguintes. Uma delas se voltou para o Estado de Rondônia, onde foi consultor e discutiu a colonização decorrente das políticas de integração e de desenvolvimento regional estabelecidas na década de 1970. Nesse momento preocupava-se com as repercussões regionais/locais dos novos processos chegados à região sob o aval do Estado. Dizia: "o que se passa em Rondônia é bem ilustrativo de como, num espaço regional ou local, ganham efeitos sociais, econômicos e espaciais as condições gerais (e particularidades) de evolução da formação social como um todo" (SANTOS, 1982b, p. 75).

Tais processos se acirraram na década de 1980 com os grandes projetos, nomeados pelo autor de "grandes objetos" de sistemas materiais. Estes configuram acréscimos no espaço, cada vez mais artificializado, conforme aconteceu na Amazônia oriental. Nesta o autor mostra que, por meio de "hidrelétricas, fábricas, fazendas modernas, portos, estradas de rodagem, estradas de ferro, cidades, o espaço é marcado por esses acréscimos, que lhe dão um conteúdo extremamente técnico" (SANTOS, 1995, p. 14).

Afora essas contribuições, em obras nas quais o autor trata do Brasil, a Amazônia figura com atributos socioespaciais importantes. É o que se percebe ao discutir a urbanização brasileira (SANTOS, 1993), momento em que as particularidades da Amazônia ajudam a reconhecer a diversidade urbanoterritorial nacional; daí a preocupação em cotejar o processo de urbanização que nela se faz presente com as demais regiões do País: "não há como confundir situações como a do Mato Grosso do Sul com a que se verifica na Amazônia. Nesta a colonização é mais descontínua, e mobiliza relativamente menos capitais e mais trabalho" (SANTOS, 1993, p. 64).

As particularidades regionais da Amazônia se fazem presentes de forma ainda mais clara em outro livro em coautoria (SANTOS; SILVEIRA, 2001). Nele é a configuração territorial brasileira e sua diversidade socioespacial no início do século XXI que se torna o centro da atenção dos autores; ocasião em que a Amazônia é caracterizada como um dos "quatro brasis" mencionados na obra. 
Pautada no critério de tecnificação do território e no entendimento da configuração do chamado meio técnico-científico informacional, a diferenciação proposta confere alguns atributos da particularidade regional, a saber: baixas densidades demográficas e técnicas, com inventário de recursos ainda a ser feito; importância das novas redes técnicas e das modernas formas de conhecimento sobre a região; convivência de diferentes sistemas de movimentos (tempos lentos e tempos rápidos); fraca centralidade do transporte e da comunicação; relações esgarçadas das cidades com suas hinterlândias e conexões com espaços extralocais; presença de nexos de globalização em áreas produtivas voltadas para a exportação; existência de cidades modernas como pontos de apoio às novas atividades (SANTOS; SILVEIRA, 2001).

No livro, a região amazônica é apresentada a partir de suas formas históricas herdadas do passado, com destaque para a presença da natureza e dos valores dos povos a ela vinculados, mas principalmente por meio de uma convivência tensa e conflitiva de tempos lentos e rápidos, que definem, respectivamente, a existência de espaços opacos e luminosos. Uma vez que ela se torna "um espaço... para os agentes hegemônicos, as ações são pontuais, precisas e pragmáticas, utilizando estradas, hidrovias e sistemas de informação, enquanto a maior parte da sociedade continua a viver em tempos mais lentos" (SANTOS; SILVEIRA, 2001, p. 104).

Sob a mesma parceria (SANTOS; SILVEIRA, 2000), uma outra obra, voltada para o tema do ensino superior como fenômeno territorial, ajuda a completar o quadro das diferenciações regionais do Brasil. Nela discute-se a densidade técnica diferenciada do território e sua relação com a distribuição territorial das instituições de ensino superior, revelando regiões, como a Amazônia, com menor presença desse serviço, não obstante o incremento, nas últimas décadas, desse nível de ensino no País. A facilidade ou não de deslocamento para ter acesso à educação, remete à questão da fluidez potencial e efetiva do território: "as condições de relativo isolamento da Amazônia, sobretudo por via terrestre, são conhecidas [...] Dependendo de sua localização, o cidadão é, assim, menos provido de meios para ter acesso aos bens e serviços" (SANTOS; SILVEIRA, 2000, p. 35).

Esse conjunto de fontes leva a uma sequência de interpretações e proposições que ratificam as particularidades regionais enunciadas pelo autor em face das outras regiões brasileiras. Com base nessas particularidades identificadas nas proposições miltonianas, buscamos sistematizar contribuições de alguns autores sobre a Amazônia cuja leitura regional se assenta no legado intelectual miltoniano, conforme procuraremos mostrar no próximo tópico.

\section{INTERPRETAÇÕES SOBRE A AMAZÔNIA A PARTIR DO LEGADO MILTONIANO}

Vários trabalhos ratificam as contribuições do autor a respeito do espaço amazônico. Muitos deles se voltam para a malha técnica e para processos que definem novos papéis para a Amazônia como uma "região do fazer" (SANTOS, 1995), com destaque para a importância de algumas atividades econômicas.

Isso pode ser constatado no dinamismo empreendido a alguns espaços produtivos, como acontece com a produção da carne bovina no Estado do Amazonas e seus nexos com o promissor mercado globalizado 
de Manaus, estudada por Billacrês (2013); assim como com o circuito espacial de produção e de cooperação da cafeicultura, responsável pela modernização do território em Cacoal, no Estado de Rondônia, pesquisado por Santos (2017).

Destaque merece ser dado aos agronegócios, como o do eixo noroeste (sul de Rondônia e porções de Mato Grosso), estudado por Frederico (2004), que discute a expansão dos circuitos espaciais de produção da soja; atividade também analisada por Silva (2010) quando mostra a expansão do meio técnico-científico informacional e a regionalização produtiva em Rondônia; e, ainda, por Lus (2012) e Ricarte (2017), que estudaram novas dinâmicas e metamorfoses socioespaciais do agronegócio globalizado no Município de Vilhena (RO), tendo em vista a expansão da fronteira tecnológica que repercute na psicosfera local.

Ainda em Rondônia, a reestruturação produtiva é vista a partir das dinâmicas populacionais e das heterogeneidades internas nos Municípios de Cerejeiras, Corumbiara e Pimenteiras do Oeste, decorrente também da produção da soja, em pesquisa realizada por Nascimento (2008), na qual o meio técnicocientífico informacional e o território usado são analisados.

Toledo (2005) aborda, por seu turno, a inserção de porções dos Estados de Rondônia e do Pará nos circuitos espaciais produtivos da soja e do cacau a partir do uso corporativo do território pela empresa Cargill, enquanto que Paixão Jr. (2012) analisa a incorporação do planalto santareno ao circuito espacial de produção da soja e seus impactos na reprodução de comunidades camponesas nos Municípios de Santarém e de Belterra.

No setor da mineração, atividades como a da exploração da bauxita, chamam a atenção de pesquisadores como Marialva (2012), que se reporta às verticalidades do circuito espacial de produção do alumínio e à resistência de relações mais horizontais no Município de Juruti (PA), onde se instalou a empresa canadense Alcoa. A mesma atividade e Município são objetos de análise de E. G. Silva (2016), que mostra a mineração como um evento global que provoca importantes impactos na ordem local de comunidades rurais.

Como exemplo de "grandes objetos" tem-se os complexos hidrelétricos, como os do Rio Madeira em Rondônia, responsáveis por transformações territoriais em distritos como Jaci-Paraná, Mutum-Paraná e Abunã, no Município de Porto Velho (RO), estudados por Cavalcante (2008). Em perspectiva semelhante, Delani (2015) também fala das hidrelétricas do Rio Madeira e da expansão do meio técnico-científico informacional, relacionando-os à difusão da dengue em Porto Velho (RO).

O turismo é outra atividade incentivada e integrada às dinâmicas locais. Faz-se presente no estudo de Azevedo Filho (2013), que analisa os transatlânticos e o Festival Folclórico de Parintins (AM) como expressões do turismo globalizado; e no de Menezes (2018), que mostra a regulação e o uso corporativo do território amazônico no período da globalização a partir da atuação do mercado de cruzeiros de luxo no Rio Amazonas. A potencialidade daquela atividade é abordada por Novo (2012) sob a ótica do turismo de base comunitária como possibilidade de fortalecer a ordem local na Região Metropolitana de Manaus (AM); e por Barreto (2015), que se refere à mesma perspectiva da atividade na comunidade ribeirinha de Anã, em Santarém (PA). 
Normalmente essas inserções de novos sistemas técnicos se voltam para o uso corporativo e competitivo do território, como no caso do transporte regional. Em trabalho sobre a reativação da malha ferroviária brasileira, Vencovsky (2006) discorre sobre o uso corporativo desse sistema na Amazônia para o transporte de produtos agrícolas e a sua expansão diretamente ligada aos interesses do agronegócio globalizado (VENCOVSKY, 2011). O mesmo se dá com os sistemas portuários, como os da Cargill, responsável pela modernização técnica e normativa do Porto de Santarém (PA) como componente de um circuito espacial, também voltado à produção da soja, objeto de análise de Toledo (2009).

Diferentes modais de transporte em conjunto são incentivadores de novos fluxos a proporcionar integração e/ou fluidez territorial entre a Amazônia e as demais regiões brasileiras, como revela Huertas (2007), que analisa a integração territorial na constituição de uma rede estruturadora de fluxos a formar uma sub-região bem particularizada. Tal fluidez, de natureza corporativa, é também vista em Manaus por Trevisan (2012), que apresenta dados da matriz origem-destino dos insumos e mercadorias do polo industrial lá instalado para o território brasileiro e para o mercado internacional, mostrando arranjos logísticos de empresas e a importância do planejamento do Estado brasileiro para esse fim. Estudo semelhante, sobre a produção e a distribuição de motocicletas no Brasil a partir da organização espacial da Moto Honda da Amazônia, localizada em Manaus (AM), é feito por Moraes (2011).

Ainda sobre o sistema logístico, tem-se o eixo de integração continental sul-americano, por meio do qual Polezi (2014) mostra a implantação de um recente sistema de engenharia na região, a Ponte Binacional Brasil-Guiana e a BR-156, com financiamento do Banco Nacional de Desenvolvimento Econômico e Social (BNDES) na fronteira norte entre Brasil e Guiana Francesa.

Tais sistemas técnicos, portadores de uma temporalidade moderna, muitas vezes convivem com práticas convencionais. É o que mostra Nahum (2006) ao discutir o sistema de objetos modernos da Albras/Alunorte em Barcarena (PA), voltado para a produção de alumínio e alumina, e o sistema de ações conservadoras da política local. A nova planificação regional, entretanto, tende mais a colocar lado a lado ordens locais e ordens globais que tensionam, ameaçam, desestruturam e remodelam relações e dinâmicas internas.

Vê-se isso na porção insular de Belém, estudada por Rodrigues (2018), que confronta as duas ordens relacionando a teoria dos circuitos da economia (SANTOS, 1979a) à atividade turística na Área de Proteção Ambiental da Ilha do Combu (Belém-PA). O mesmo confronto se constata na titulação do território quilombola de Araquembaua (Baião-PA), analisado por Lopes (2017); e na tensão, espacial e institucional, do uso do território do povo indígena Tembé-Turé-Mariquita, impactado por sistemas de engenharia ligados a empresas de mineração e de dendeicultura no Município de Tomé-Açu (PA), analisado por Thury (2017).

Tal entendimento se faz presente também na produção e na circulação do açaí no Baixo Tocantins (PA); atividade esta que, feita agora também em escalas ampliadas, traz impactos à vida local, conforme mostra Corrêa (2010), ao abordar repercussões da globalização desse produto nos modos de vida de 
comunidades ribeirinhas de Cacoal e Cuxipiarí (Cametá-Pará), contrapondo o uso do território como abrigo em relação àquele considerado como recurso.

A potencialidade natural coloca a região em relação direta com outras regiões e agentes interessados no seu aproveitamento econômico, seja dos recursos hídricos, estudados por Rodrigues (2011), problematizando a questão da soberania regional em face da globalização; seja dos produtos fitoterápicos, estudados por Ribeiro (2015), que mostra o aproveitamento e formas de uso do território que geram sinergia técnica entre saber local e saber universalizado. Notadamente, a nova configuração regional sugere desestruturação de solidariedades preexistentes, a exemplo do que ocorreu na Vila Santo Antônio e na Comunidade Babaquara, na microrregião de Altamira (PA), com a instalação do complexo de Belo Monte, como mostra D. C. Silva (2016). As ondas de modernização chegadas com as frentes de expansão econômica implicaram na remodelação daquelas dinâmicas que se voltavam às lógicas regionais mais internas do circuito inferior, conforme também se vê em Rondônia e no Acre, analisados por Pereira (2009).

Em vários estudos os tempos lentos são associados ao circuito inferior da economia ou às necessidades das populações da região, como se vê em relação ao sistema de transporte mais alternativo, estudado por Ferreira (2011), que mostra a necessidade de uma política nesse setor mais atenta às particularidades e ritmos próprios de passageiros nas ilhas da Região Metropolitana de Belém.

Trata-se, todavia, de práticas que, mesmo associadas a cotidianos do tempo mais lento da população regional, não estão isentas de modernização, em razão da presença de atributos do atual período técnicocientífico informacional que convive com práticas econômicas ditas "marginais", a exemplo da pirataria no setor de produção cultural, analisado por Tozi (2013), em seu estudo sobre a economia urbana do ritmo musical do tecnobrega em Belém (PA).

Mais do que contraponto, portanto, a presença desses tempos no espaço regional revela hibridez, conforme se apreende em Salim Filho (2007) em relação ao mercado de trabalho e o serviço de transporte alternativo de mototáxis como componentes do circuito superior marginal - que contém o circuito superior e o inferior - em Castanhal (Pará) e Tefé (Amazonas); e como se vê em Bicudo Jr. (2006), ao analisar os tempos rápidos e lentos nas ações "marginais" dos pequenos laboratórios e distribuidores de medicamentos na Amazônia.

Muitas dessas atividades ganham relevância nos espaços urbanos da região, redefinindo-os não apenas internamente como também na sua relação para com o entorno regional e sub-regional nas quais estão inseridas. Nesse sentido, identifica-se outro grupo de trabalhos preocupados em interpretar essas questões à luz dos aportes teórico-conceituais miltonianos. A globalização dos lugares é objeto de preocupação de Silva (2011) ao abordar as empresas de fast food em bairros pericentrais da cidade de Belém (PA). A verticalização urbana é, por sua vez, objeto de estudo de Souza (2016) que, à luz dos conceitos de tecnosfera e de psicosfera, situa, a exemplo de Medeiros (1996), Manaus (AM) no período da globalização.

Andrade (2014) mostra mudanças e permanências na realidade regional, analisando a globalização do açaí e as manifestações diferenciadas de sua gastronomia na Grande Belém (PA) por meio dos circuitos 
da economia urbana. Outros trabalhos seguem linhas semelhantes, apoiados também nessa teoria miltoniana. É o caso de Medeiros (2010), que analisa a distribuição geográfica das feiras livres em Belém (PA), reconhecendo-as como atividades do circuito inferior marcadas, sobretudo, por solidariedades orgânicas.

As particularidades de Belém são cotejadas com outras metrópoles regionais no trabalho de Montenegro (2012), que discute metamorfoses do circuito inferior a partir de portos, feiras e bairros periféricos nessa cidade. A presença daquele circuito na produção imobiliária de Belém, especificamente na Ilha de Mosqueiro, expressa, no trabalho de Ferreira (2012), uma particularidade da dispersão metropolitana regional; dispersão essa que é igualmente motivo de reflexão de Mendes (2014), que se ocupou da conformação de uma nova (sub)centralidade suburbana em Belém (PA) a partir da atuação de um circuito superior imobiliário, comercial, financeiro e de serviços.

Para além do intraurbano, a teoria dos circuitos é referenciada em outros trabalhos que tratam da relação cidade-região. É assim que essa teoria se faz presente no estudo sobre Marabá, feito por Nunes (2015), para entender a relação das feiras livres e das feiras de exposição como manifestações diferenciadas da relação cidade e entorno; assim como se faz presente em estudo de Trindade (2015) sobre Santarém, voltado para os impactos da produção e da circulação da soja nos circuitos da economia urbana dessa cidade média amazônica.

Essa mesma relação cidade-região é analisada por meio das noções miltonianas de horizontalidades e de verticalidades, como faz Ribeiro (2010), para entender a centralidade urbano-regional de Marabá (PA) no sudeste paraense; em Euzébio (2012), que analisa a fluidez, a porosidade territorial e a horizontalidade interurbana na produção da centralidade das cidades gêmeas de Tabatinga e Leticia na fronteira do Brasil e Colômbia; em Souza (2014), que estuda os nexos multiescalares do comércio peruano na cidade fronteiriça de Benjamin Constant (AM); em Queiroz $(2011,2015)$ que estuda, respectivamente, a rede elétrica e a integração territorial pontual de uma cidade de importância regional como Tefé (AM), e também os fluxos virtuosos e desintegradores na configuração da centralidade periférica dessa mesma cidade do Médio Solimões. Anjos (2014) se reporta às redes intra e interlocais estabelecidas pela Área de Livre Comércio de Boa Vista (RR); e Raposo (2015) à (re)produção do espaço urbano de Pacaraima (RR).

Por fim, alguns trabalhos preocupados em pensar o espaço como condição de cidadania, também encontram abrigo em teorias e conceitos miltonianos. É o caso de Campos (2011), que mostra as possibilidades de apropriação das redes informacionais, um dos atributos do meio técnico-científico informacional, na educação à distância no Estado do Amazonas; de Novaes (2012), que analisa o processo participativo do Congresso da Cidade de Belém (PA) como projeto coletivo e contra hegemônico de uso do território no período da globalização; e de Costa (2013), que estuda o meio técnico-científico informacional, a gestão previdenciária e a cidadania da população idosa na cidade de Lábrea (AM). 


\section{CONSIDERAÇÕES FINAIS}

A análise do material documental e bibliográfico revisado, além de mostrar elementos centrais do pensamento miltoniano, revela o potencial de sua reflexão para compreender a dinâmica mais recente do espaço amazônico. Dessa forma, no decorrer da argumentação buscou-se mostrar que, na construção de uma teoria crítica para a geografia, chamada por ele de Geografia Nova, há um lugar reservado à Amazônia no conjunto da obra deixada pelo autor.

É dessa maneira que esse intelectual brasileiro, mesmo não tendo como preocupação central a Amazônia, estabeleceu importantes reflexões a propósito dessa região. Revelam-se, no contexto de suas discussões, particularidades socioespaciais do espaço amazônico em face dos processos de modernização que caracterizam o território brasileiro contemporâneo. Mas, para além disso, seu pensamento, com suas teorias e categorias interpretativas, tem ajudado muitos pesquisadores que estudam a região amazônica a entender sua dinâmica do ponto de vista socioespacial, ratificando, assim, algumas de suas particularidades já anunciadas anteriormente em produções do autor.

É diante disso que se torna possível falar de uma Amazônia cuja leitura é dada a partir das premissas teóricas e conceituais miltonianas, situadas especialmente em alguns eixos temáticos que aqui buscamos apresentar a partir dessa produção por nós levantada, sistematizada e analisada à luz das contribuições do autor em referência.

\section{REFERÊNCIAS}

ANDRADE, M. C. A terra e o homem no Nordeste: contribuição ao estudo da questão agrária no Nordeste. 5. ed. São Paulo: Atlas, 1986.

ANDRADE, S. S. Põe tapioca, põe farinha d'água? Gastronomia do açaí e identidade socioespacial e cultural na Grande Belém. 2014. 258f. Tese (Doutorado em Ciências - Desenvolvimento Socioambiental) Programa de Pós-Graduação em Desenvolvimento Sustentável do Trópico Úmido, Núcleo de Altos Estudos Amazônicos, Universidade Federal do Pará, Belém, 2014.

ANJOS, J. N. S. Desenvolvimento regional da Área de Livre Comércio de Boa Vista e suas implicações socioespaciais a partir de um estudo geoestratégico. 2014. 130f. Dissertação (Mestrado) - Programa de PósGraduação em Geografia, Instituto de Geociências, Universidade Federal de Roraima, Boa Vista, 2014.

ARQUIVO INSTITUTO DE ESTUDOS BRASILEIROS [IEB]. Fundo/Coleção Milton Santos. São Paulo: Autor, 2017.

AZEVEDO FILHO, J. D. M. A produção e a percepção do turismo em Parintins, Amazonas. 2013. 210f. Tese (Doutorado em Geografia Humana) - Departamento de Geografia, Faculdade de Filosofia, Letras e Ciências Humanas, Universidade de São Paulo, São Paulo, 2013.

BARRETO, E. O. Turismo de base comunitária e uso do território em comunidade ribeirinha da Amazônia paraense: o caso de Anã no Município de Santarém/Pará. 2015. 159f. Dissertação (Mestrado) - Programa de Pós-Graduação em Geografia, Faculdade de Filosofia e Ciências Humanas, Universidade Federal do Pará, Belém, 2015.

BICUDO JR., E. C. O circuito superior marginal: produção de medicamentos e o território brasileiro. 2006. 286f. Dissertação (Mestrado em Geografia Humana) - Departamento de Geografia, Faculdade de Filosofia, Letras e Ciências Humanas, Universidade de São Paulo, São Paulo, 2006.

BILLACRÊS, M. A. R. Circuito espacial de produção de carne bovina no Estado do Amazonas. 2013. $146 \mathrm{f}$. Dissertação (Mestrado em Geografia) - Programa de Pós-Graduação em Geografia, Instituto de Ciências Humanas e Letras, Universidade Federal do Amazonas, Manaus, 2013. 
CAMPOS, I. A. M. Territórios conectados pela educação à distância no Amazonas. 2011. 217f. Tese (Doutorado em Geografia Humana) - Departamento de Geografia, Faculdade de Filosofia, Letras e Ciências Humanas, Universidade de São Paulo, São Paulo, 2011.

CASTRO, J. Ouvindo Josué de Castro - homem força do nosso tempo (entrevista a Araújo Dantas - 1965). In: CASTRO, A. M. (Org.) Fome, um tema proibido: últimos escritos de Josué de Castro. 2. ed. Petrópolis: Vozes, 1984. p. 111-115.

CAVAlCANTE, M. M. A. Transformações territoriais no Alto Rio Madeira: hidrelétricas, tecnificação e (re)organização. 2008. 112f. Dissertação (Mestrado em Geografia) - Programa de Pós-Graduação em Geografia, Núcleo de Ciências Exatas e da Terra, Universidade Federal de Rondônia, Porto Velho, 2008.

CORRÊA, R. B. Do território recurso ao território abrigo: modo de vida e o processo de valorização do açaí no Município de Cametá-PA. 2010. 122f. Dissertação (Mestrado) - Programa de Pós-Graduação em Geografia, Faculdade de Filosofia e Ciências Humanas, Universidade Federal do Pará, Belém, 2010.

COSTA, D. P. A economia da cidade somos nós. Envelhecimento populacional e gestão previdenciária no Brasil: o Amazonas em foco. 2013. 207f. Tese (Doutorado em Geografia Humana) - Departamento de Geografia, Faculdade de Filosofia, Letras e Ciências Humanas, Universidade de São Paulo, São Paulo, 2013. DELANI, D. Meio natural, meio técnico e epidemiologia: as hidrelétricas e a difusão da dengue no Complexo do Rio Madeira (Porto Velho, RO). 2015. 271f. Dissertação (Mestrado) - Departamento de Geografia, Faculdade de Filosofia, Letras e Ciências Humanas, Universidade de São Paulo, São Paulo, 2015. EUZÉBIO, E. F. Fronteira e horizontalidade na Amazônia: as cidades gêmeas de Tabatinga (Brasil) e Leticia (Colômbia). 2012. 168f. Dissertação (Mestrado) - Departamento de Geografia, Faculdade de Filosofia, Letras e Ciências Humanas, Universidade de São Paulo, São Paulo, 2012.

FERREIRA, R. C. B. Análise dos circuitos de produção, reprodução e subsistência do transporte hidroviário de passageiros nas ilhas da Região Metropolitana de Belém: uma contribuição para a revitalização do setor. 2011. 154f. Tese (Doutorado em Ciências - Desenvolvimento Socioambiental) Programa de Pós-Graduação em Desenvolvimento Sustentável do Trópico Úmido, Núcleo de Altos Estudos Amazônicos, Universidade Federal do Pará, Belém, 2011.

FERREIRA, S. B. A expansão dos assentamentos residenciais na Ilha de Mosqueiro: uma particularidade de dispersão urbana no espaço metropolitano de Belém (PA). 2012. 138f. Dissertação (Mestrado em Geografia) - Programa de Pós-Graduação em Geografia, Faculdade de Filosofia e Ciências Humanas, Universidade Federal do Pará, Belém, 2012.

FREDERICO, S. Sistemas de movimentos no território brasileiro: os novos circuitos espaciais produtivos da soja. 2004. 210f. Dissertação (Mestrado em Geografia) - Programa de Pós-Graduação em Geografia, Instituto de Geociências, Universidade Estadual de Campinas, Campinas, 2004.

HUERTAS, D. M. Da fachada atlântica ao âmago da hiléia: integração nacional e fluidez territorial no processo de expansão da fronteira agrícola. 2007. 315f. Dissertação (Mestrado) - Departamento de Geografia, Faculdade de Filosofia, Letras e Ciências Humanas, Universidade de São Paulo, São Paulo, 2007.

LOPES, C. J. O. O território quilombola de Araquembaua, Baião-PA. Dissertação (Mestrado em Geografia). 2017. 141f. - Programa de Pós-Graduação em Geografia, Faculdade de Filosofia e Ciências Humanas, Universidade Federal do Pará, Belém, 2017.

LUS, D. A. Dinâmica socioespacial do agronegócio em Vilhena: uma análise sobre a expansão da fronteira tecnológica. 2012. 120f. Dissertação (Mestrado em Geografia) - Programa de Pós-Graduação em Geografia, Núcleo de Ciências Exatas e da Terra, Universidade Federal de Rondônia, Porto Velho, 2012.

MARIALVA, D. A. Novas dinâmicas territoriais na Amazônia: desdobramentos da mineração da bauxita em Juruti (PA). 2012. 98f. Dissertação (Mestrado em Geografia Humana) - Departamento de Geografia, Faculdade de Filosofia, Letras e Ciências Humanas, Universidade de São Paulo, São Paulo, 2012.

MARINO, L. F. Manuel Correia de Andrade: um geógrafo voltado para as causas sociais. In: MACHADO, M. S; MARTIN, A. R. (Orgs.). Dicionário dos geógrafos brasileiros. Rio de Janeiro: 7 Letras, 2014. v. 1. p. 101- 117.

MEDEIROS, I. A. Globalização dos lugares: a verticalização em Manaus. 1996. 106f. Dissertação (Mestrado em Geografia Humana) - Departamento de Geografia, Faculdade de Filosofia, Letras e Ciências Humanas, Universidade de São Paulo, São Paulo, 1996. 
MEDEIROS, J. F. S. As feiras livres em Belém (PA): dimensão geográfica e existência cotidiana. 2010. 118f. Dissertação (Mestrado em Geografia) - Programa de Pós-Graduação em Geografia, Faculdade de Filosofia e Ciências Humanas, Universidade Federal do Pará, Belém, 2010.

MENDES, L. A. S. Espaços elitizados de moradia e consumo: a reestruturação urbana da Avenida Augusto Montenegro no quadro das centralidades da Região Metropolitana de Belém. 2014. 210f. Dissertação (Mestrado em Geografia) - Programa de Pós-Graduação em Geografia, Faculdade de Filosofia e Ciências Humanas, Universidade Federal do Pará, Belém, 2014.

MENEZES, T. Z. Cruzeiros de luxo no rio Amazonas: da regulação ao uso corporativo do território. 2018. 171f. Dissertação (Mestrado em Geografia Humana) - Departamento de Geografia, Faculdade de Filosofia, Letras e Ciências Humanas, Universidade de São Paulo, São Paulo, 2018.

MONTENEGRO, M. R. Globalização, trabalho e pobreza no Brasil metropolitano: o circuito inferior da economia urbana em São Paulo, Brasília, Fortaleza e Belém. 2012. 291f. Tese (Doutorado). Departamento de Geografia, Faculdade de Filosofia, Letras e Ciências Humanas, Universidade de São Paulo, São Paulo, 2012. MORAES, E. O. Corporação em rede: um estudo sobre a Moto Honda da Amazônia. 2011. 92f. Dissertação (Mestrado em Geografia) - Programa de Pós-Graduação em Geografia, Instituto de Ciências Humanas e Letras, Universidade Federal do Amazonas, Manaus, 2011.

MOREIRA, R. O pensamento geográfico brasileiro: as matrizes brasileiras. São Paulo: Contexto, 2010. v. 3. NAHUM, J. S. O uso do território em Barcarena: modernização e ações políticas conservadoras. 2006. 126f. Tese (Doutorado em Geografia) - Programa de Pós-Graduação em Geografia, Instituto de Geociências e Ciências Exatas, Universidade Estadual Paulista, Rio Claro, 2006.

NASCIMENTO, M. L. Reorganização dos espaços de produção agrícola da soja: análise dos Municípios de Cerejeiras, Corumbiara e Pimenteiras do Oeste-RO - 1990 a 2008. 2008. 142f. Dissertação (Mestrado em Geografia) - Programa de Pós-Graduação em Geografia, Núcleo de Ciências Exatas e da Terra, Universidade Federal de Rondônia, Porto Velho, 2008.

NOVAES, J. S. Território e lugar: a construção democrática da metrópole - o Congresso da Cidade de Belém do Pará. 2012. 420f. Tese (Doutorado em Geografia Humana) - Departamento de Geografia, Faculdade de Filosofia, Letras e Ciências Humanas, Universidade de São Paulo, São Paulo, 2012.

NOVO, C. B. M. C. Turismo de base comunitária na Região Metropolitana de Manaus: caracterização e análise crítica. 2012. 141f. Dissertação (Mestrado em Geografia Humana) - Departamento de Geografia, Faculdade de Filosofia, Letras e Ciências Humanas, São Paulo, 2012.

NUNES, D. A. Feiras livres \& feiras de exposição: expressões da relação cidade-floresta no sudeste paraense. 2015. 256f. Dissertação (Mestrado em Planejamento do Desenvolvimento) - Programa de PósGraduação em Desenvolvimento Sustentável do Trópico Úmido, Núcleo de Altos Estudos Amazônicos, Universidade Federal do Pará, Belém, 2015.

PAIXÃO JR., P. R. C. Uso do território e gênero de vida na Amazônia: reprodução camponesa e agronegócio no Planalto Santareno. 2012. 134f. Dissertação (Mestrado) - Programa de Pós-Graduação em Geografia, Faculdade de Filosofia e Ciências Humanas, Universidade Federal do Pará, Belém, 2012.

PEREIRA, M. F. V. O processo recente de atualização do território no sudoeste da Amazônia: lógicas exógenas e dialéticas endógenas em Rondônia e Acre. 2009. 329f. Tese (Doutorado em Geografia) Programa de Pós-Graduação em Geografia, Instituto de Geociências e Ciências Exatas, Universidade Estadual Paulista, Rio Claro, 2009.

POLEZI, C. O BNDES e o financiamento da integração sul-americana: sistemas de engenharia na fronteira Brasil-Guiana Francesa. 2014. 213f. Dissertação (Mestrado em Geografia Humana) - Departamento de Geografia, Faculdade de Filosofia, Letras e Ciências Humanas, Universidade de São Paulo, São Paulo, 2014. QUEIROZ, K. O. A rede elétrica na cidade de Tefé como instrumento de análise de integração territorial. 2011. 207f. Dissertação (Mestrado em Geografia Humana) - Departamento de Geografia, Faculdade de Filosofia, Letras e Ciências Humanas, Universidade de São Paulo, São Paulo, 2011.

QUEIROZ, K. O. Centralidade periférica e integração relativizada: uma leitura de Tefé no Amazonas. 2015. 325f. Tese (Doutorado em Geografia Humana) - Departamento de Geografia, Faculdade de Filosofia, Letras e Ciências Humanas, Universidade de São Paulo, São Paulo, 2015.

RAPOSO, T. J. N. A (re)produção do espaço urbano no Município de Pacaraima - 1995-2013. 2015. $263 f$. Dissertação (Mestrado em Geografia) - Programa de Pós-Graduação em Geografia, Instituto de Geociências, Universidade Federal de Roraima, Boa Vista, 2015. 
RIBEIRO, L. H. L. Território e macrossistema de saúde: os programas de fitoterapia no Sistema Único de Saúde (SUS). 2015. 305f. Tese (Doutorado em Geografia) - Programa de Pós-Graduação em Geografia, Instituto de Geociências, Universidade Estadual de Campinas, Campinas, 2015.

RIBEIRO, R. As cidades médias e a reestruturação da rede urbana amazônica: a experiência de Marabá no sudeste paraense. 2010. 134f. Dissertação (Mestrado em Geografia Humana) - Departamento de Geografia, Faculdade de Filosofia, Letras e Ciências Humanas, Universidade de São Paulo, São Paulo, 2010.

RICARTE, C. A. A. A psicosfera do espaço agrário de Vilhena: contradições entre o agronegócio e o campesinato. 2017. 167f. Dissertação (Mestrado em Geografia) - Programa de Pós-Graduação em Geografia, Núcleo de Ciências Exatas e da Terra, Universidade Federal de Rondônia, Porto Velho, 2017.

RODRIGUES, E. B. Território e soberania na globalização: Amazônia, jardim de águas sedento. 2010. 404f. Tese (Doutorado em Geografia Humana) - Departamento de Geografia, Faculdade de Filosofia, Letras e Ciências Humanas, Universidade de São Paulo, São Paulo, 2010.

RODRIGUES, A. F. A. C. A produção do espaço pelo e para o turismo na Área de Proteção Ambiental da Ilha do Combu (Belém-Pará). 2018. 331f. Dissertação (Mestrado em Planejamento do Desenvolvimento) Programa de Pós-Graduação em Desenvolvimento Sustentável do Trópico Úmido, Núcleo de Altos Estudos Amazônicos, Universidade Federal do Pará, Belém, 2018.

SALIM FILHO, M. T. Políticas públicas e trabalho no transporte alternativo na Amazônia: moto-táxi. 2007. 223f. Dissertação (Mestrado em Planejamento do Desenvolvimento) - Programa de Pós-Graduação em Desenvolvimento Sustentável do Trópico Úmido, Núcleo de Altos Estudos Amazônicos, Universidade Federal do Pará, Belém, 2007.

SANTOS, M. O espaço dividido: os dois circuitos da economia urbana dos países subdesenvolvidos. Rio de Janeiro: Francisco Alves, 1979a.

SANTOS, M. Do espaço sem nação ao espaço transnacionalizado. In: RATTNER, H. (Org.) Brasil: caminhos alternativos do desenvolvimento. São Paulo: Brasiliense, 1979b. 143-161.

SANTOS, M. Espaço e sociedade: ensaios. Petrópolis: Vozes, 1982a.

SANTOS, M. Organização do espaço e organização social: o caso de Rondônia. Boletim Carioca de Geografia, Rio de Janeiro, n. 33, p. 51-77, 1982b.

SANTOS, M. Por uma geografia nova: da crítica da geografia a uma geografia crítica. 3. ed. São Paulo: Hucitec, 1986.

SANTOS, M. O espaço do cidadão. São Paulo: Nobel, 1987.

SANTOS, M. A urbanização brasileira. São Paulo: Hucitec, 1993.

SANTOS, M. Os grandes projetos: sistema de ação e dinâmica espacial. In: CASTRO, E.; MOURA, E.; MAIA, M. L. (Orgs.). Industrialização e grandes projetos: desorganização e reorganização do espaço. Belém: NAEA-UFPA, 1995. p. 13-20.

SANTOS, M. O território e o saber local: algumas categorias de análise. Cadernos IPPUR, Rio de Janeiro, ano XIII, n. 2, p. 15-26, ago./dez. 1999.

SANTOS, M. Por uma outra globalização: do pensamento único à consciência universal. São Paulo: Record, 2000a.

SANTOS, M. De volta ao Brasil. In: SEABRA, O; CARVALHO, M.; LEITE, J. C. Território e sociedade: entrevista com Milton Santos. São Paulo: Fundação Perseu Abramo, 2000b.

SANTOS, M.; SILVEIRA, M. L. O ensino superior público e particular e o território brasileiro. Brasília: Abmes, 2000.

SANTOS, M.; SILVEIRA, M. L. O Brasil: território e sociedade no início do século XXI. Rio de Janeiro: Record, 2001.

SANTOS, T. R. S. Circuito espacial de produção e círculos de cooperação na cafeicultura em Cacoal/Rondônia. 2017. 200f. Dissertação (Mestrado em Geografia) - Programa de Pós-Graduação em Geografia, Núcleo de Ciências Exatas e da Terra, Universidade Federal de Rondônia, Porto Velho, 2017.

SILVA, D. C. Uma interpretação geográfica dos impactos da Hidrelétrica Belo Monte: estudo de caso da Vila Santo Antônio e da Comunidade Babaquara na Microrregião de Altamira-PA. 2016. 143f. Dissertação (Mestrado em Geografia) - Programa de Pós-Graduação em Geografia, Faculdade de Filosofia e Ciências Humanas, Universidade Federal do Pará, Belém, 2016. 
SILVA, E. G. Território, mineração e modos de vida em comunidades rurais em Juruti - (PA). 2016. 131f. Dissertação (Mestrado em Geografia) - Programa de Pós-Graduação em Geografia, Faculdade de Filosofia e Ciências Humanas, Universidade Federal do Pará, Belém, 2016.

SILVA, M. E. C. Paisagem e lugar na Amazônia produzidos pela globalização: uma análise a partir das empresas de fast food nos bairros de Nazaré e Umarizal, Belém-PA. 2011. 136f. Dissertação (Mestrado em Geografia) - Programa de Pós-Graduação em Geografia, Faculdade de Filosofia e Ciências Humanas, Universidade Federal do Pará, Belém, 2011.

SILVA, R. G. C. Dinâmicas territoriais em Rondônia: conflitos na produção e uso do território no período de 1970/2010. 2010. 222f. Tese (Doutorado em Geografia Humana) - Departamento de Geografia, Faculdade de Filosofia Letras e Ciências Humanas, Universidade de São Paulo, São Paulo, 2010.

SOUZA, A. S. N. A cidade na fronteira: expansão do comércio peruano em Benjamin Constant no Amazonas-Brasil. 2014. 153f. Dissertação (Mestrado em Geografia)-Programa de Pós-Graduação em Geografia, Instituto de Ciências Humanas e Letras, Universidade Federal do Amazonas, Manaus, 2014.

SOUZA, L. C. Espaço e tempo na cidade de Manaus: processo de verticalização 1970 a 2010. 2016. $156 f$. Dissertação (Mestrado em Geografia) - Programa de Pós-Graduação em Geografia, Instituto de Ciências Humanas e Letras, Universidade Federal do Amazonas, Manaus, 2016.

THURY, J. P. C. Tensões territoriais na Amazônia paraense: o povo indígena Tembé-Turé-Mariquita no Município de Tomé-Açu. 2017. 101f. Dissertação (Mestrado em Geografia) - Programa de Pós-Graduação em Geografia, Faculdade de Filosofia e Ciências Humanas, Universidade Federal do Pará, Belém, 2017.

TOLEDO, M. R. Circuitos espaciais da soja, da laranja e do cacau no Brasil: uma nota sobre o papel da Cargill no uso corporativo do território brasileiro. 2005. 305f. Dissertação (Mestrado em Geografia) Programa de Pós-Graduação em Geografia, Instituto de Geociências, Universidade Estadual de Campinas, Campinas, 2005.

TOLEDO, M. R. O mundo no lugar: o atual projeto de modernização no município de Santarém (PA) (A viabilidade do território brasileiro para uso corporativo e a modernização do Porto de Santarém). 2009. 154f. Tese (Doutorado em Geografia) - Programa de Pós-Graduação em Geografia, Instituto de Geociências e Ciências Exatas, Universidade Estadual Paulista, Rio Claro, 2009.

TOZI, F. Rigidez normativa e flexibilidade tropical: investigando os objetos técnicos no período da globalização. 2012. 262f. Tese (Doutorado em Geografia Humana) - Departamento de Geografia, Faculdade de Filosofia, Letras e Ciências Humanas, Universidade de São Paulo, São Paulo, 2013.

TREVISAN, L. Os usos do território brasileiro e o imperativo da logística: uma análise a partir da Zona Franca de Manaus. 2012. 282f. Tese (Doutorado em Geografia) - Programa de Pós-Graduação em Geografia, Instituto de Geociências, Universidade Estadual de Campinas, Campinas, 2012.

TRINDADE, G. O. A cidade \& a soja: impactos da produção e da circulação de grãos nos circuitos da economia urbana de Santarém-Pará. 2015. 127f. Dissertação (Mestrado em Planejamento do Desenvolvimento) - Programa de Pós-Graduação em Desenvolvimento Sustentável do Trópico Úmido, Núcleo de Altos Estudos Amazônicos, Universidade Federal do Pará, Belém, 2015.

TRINDADE JR., S-C. C. Um lugar para pensar a Amazônia? Revisitando a Geografia Nova e o pensamento crítico miltoniano. In: ENCUENTRO DE GEÓGRAFOS DE AMÉRICA LATINA, XVII, 2019, Quito, Memorias del XVII Encuentro de Geógrafos de América Latina (Anales)... Quito: Pontificia Universidad Católica del Ecuador, 2019. p. 1-16. Disponível em: <https://www.puce.edu.ec/sitios/egal2019/>. Acesso em: 24 set. 2019.

VENCOVSKY, V. P. Sistema ferroviário e o uso do território brasileiro: uma análise do movimento de produtos agrícolas. 2006. 150f. Dissertação (Mestrado em Geografia) - Programa de Pós-Graduação em Geografia, Instituto de Geociências, Universidade Estadual de Campinas, Campinas, 2006.

VENCOVSKY, V. P. Ferrovia e logística do agronegócio globalizado: avaliação das políticas públicas e privadas do sistema ferroviário brasileiro. 2011. 198f. Tese (Doutorado em Geografia) - Programa de PósGraduação em Geografia, Instituto de Geociências, Universidade Estadual de Campinas, Campinas, 2011.

Texto recebido em: 18/12/2019

Texto aprovado em: 11/03/2020 